\title{
Body fat and dairy product intake in lactase persistent and non-persistent children and adolescents
}

\author{
Ricardo Almon '*, Emma Patterson ${ }^{2,3}$, Torbjörn K. Nilsson ${ }^{4}$, \\ Peter Engfeldt' and Michael Sjöström²
}

'Family Medicine Research Centre, School of Health and Medical Sciences, Örebro University, Örebro, Sweden; ${ }^{2}$ Unit for Preventive Nutrition, Department of Biosciences and Nutrition, Karolinska Institute, S- I4I 57 Huddinge, Sweden; ${ }^{3}$ School of Biological Sciences, Dublin Institute of Technology, Dublin, Ireland; ${ }^{4}$ Department of Laboratory Medicine, Clinical Chemistry, Örebro University Hospital, Örebro, Sweden

Abstract

Background: Lactase non-persistent (LNP) individuals may be lactose intolerant and therefore on a more restricted diet concerning milk and milk products compared to lactase persistent (LP) individuals. This may have an impact on body fat mass.

Objective: This study examines if LP and LNP children and adolescents, defined by genotyping for the LCT$13910 \mathrm{C}>\mathrm{T}$ polymorphism, differ from each other with regard to milk and milk product intake, and measures of body fat mass.

Design: Children ( $n=298$, mean age 9.6 years) and adolescents ( $n=386$, mean age 15.6 years), belonging to the Swedish part of the European Youth Heart Study, were genotyped for the LCT-13910 C $>$ T polymorphism. Dietary intakes of reduced and full-fat dairy varieties were determined.

Results: LNP (CC genotype) subjects consumed less milk, soured milk and yoghurt compared to LP (CT/TT genotype) subjects $(p<0.001)$. Subsequent partitioning for age group attenuated this observation $(p=0.002$ for children and $p=0.023$ in adolescents). Six subjects were reported by parents to be 'lactose intolerant', none of whom were LNP. LNP children and adolescents consumed significantly less reduced fat milk and milk products than LP children and adolescents ( $p=0.009$ for children and $p=0.001$ for adolescents).

Conclusions: We conclude that LP is linked to an overall higher milk and dairy intake, but is not linked to higher body fat mass in children and adolescents.

Keywords: milk consumption; lactose intolerance; LCT-13910 C > T polymorphism; obesity; nutrigenetics

Received: 13 March 2010; Revised: 15 May 20I0; Accepted: 25 May 20I0; Published: 16 June 2010

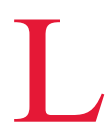
actase non-persistence (LNP) is an inherited condition defined as the inability to digest lactose due to a reduced production of lactase after weaning (1). A single nucleotide polymorphism (SNP) located $14 \mathrm{~kb}$ upstream of the lactase gene (LCT-13910 $\mathrm{C}>\mathrm{T}$ ) has been shown to be associated with lactase persistence (LP). The T allele appears to be dominant over the C allele that represents LNP (2-4). LP (CT/TT genotype) is thus a dominant trait controlled by the lactase gene (LCT). LNP (CC genotype) is also known as adult-type hypolactasia $(\mathrm{AtH})$ or primary hypolactasia (5). Homozygosity for the $\mathrm{C}$ allele contributes to the restricted consumption of fresh milk and some dairy products to approximately $12 \mathrm{~g}$ of lactose or two cups of milk daily (6). The perception of symptoms related to lactose maldigestion can nevertheless vary between single subjects with LNP and even LP.

The underlying hypothesis of this study is that LP and LNP might influence the consumption of milk and milk products in children and adolescents, which in turn could be associated with differences in body fat mass between LP and LNP.

Some studies suggest that dairy products may help prevent weight gain and promote weight loss in children and adolescents (7-10). Other studies, in contrast, have not found an effect of milk and milk product intake on body fat mass (11-14), or shown increased weight gain in children and adolescents (15). Also, a recent review suggests that the 'dogma' of promoting the intake of reduced fat diary should be readdressed by interventional 
studies. The authors conclude that reduced fat varieties of dairy products could constitute a significant contributory factor to hyperphagia and obesity observed in children and adolescents (16). Thus, the role of cow's milk consumption in relation to childhood and adolescent obesity is debated and remains controversial.

The main purpose of this study is to examine if children and adolescents with and without the LCT$13910 \mathrm{C}>\mathrm{T}$ polymorphism differed in their intakes of milk and milk products, and thereby in measures of body fat mass. Full- and low-fat varieties of milk and milk products were studied.

\section{Subjects and methods}

\section{Population}

Blood samples were obtained from 686 subjects (300 children and 386 adolescents) belonging to the Swedish part of the European Youth Heart Study (EYHS). EYHS is a cross-sectional school-based study of risk factors for future cardiovascular disease among children (9-10 years old) and adolescents (15-16 years old). The mean ages in the Swedish sample for children and adolescents were 9.6 years and 15.6 years, respectively. Sampling procedures and participation rates have been described previously (17).

\section{Anthropometric variables}

Height, weight, hip and waist circumferences were measured by internationally accepted standardized procedures (18). Body mass index (BMI) was calculated as weight $/$ height $^{2}\left(\mathrm{~kg} / \mathrm{m}^{2}\right)$. Body fat percentage was calculated by using Slaughter's equation based on skinfold thickness measurements (19). These measurements have been shown to correlate highly with dual-energy X-ray absorptiometry-measured body fat percentages in children of similar age groups (20). These measurements were taken using a Harpenden caliper at the biceps, triceps, subscapular, suprailiac and triceps surae sites on the left side of the body. All measurements were taken twice and then the mean thickness was calculated. If the first two measurements differed by more than $2 \mathrm{~mm}$, a third measurement was taken and the two closest measurements were averaged.

\section{Dietary variables}

The consumption of milk and milk products was assessed by an interviewer-mediated 24-hour recall. In the nineyear olds, a qualitative food record completed the day before the interview with the help of parents served as a checklist for the data obtained during the recall. A food atlas was used to estimate portion sizes. Dietary data were processed by StorMats (version 4.02, Rudans Lättdata, Sweden) and analysed using the Swedish National Food database (version 99.1). The milk products of interest were milk, soured milk (a traditional milk product, 'filmjölk', in Swedish), yoghurt and cheese, both reducedand full-fat versions. As part of a broad-ranging questionnaire, parents of the participants were asked if their child had a chronic illness or adhered to a special diet.

\section{Genetic analysis}

For the genetic analysis genomic DNA was isolated from whole blood samples EDTA from the individuals with the QIAamp DNA Blood Mini Kit spin procedure. The DNA fragment spanning the $-13910-\mathrm{C} / \mathrm{T}$ polymorphic site was amplified using a biotinylated forward-primer (5'-GGGCTGGCAATACAGATAAGATA-3') and an unbiotinylated reverse-primer (5'-AGCAGGGCTCAAA GAACAATCTA-3'). The applied sequencing primer was: 5'-CTTTGAGGCCAGGG-3'. Sequencing was performed using a PSQ96 SNP reagent Kit and a PSQ 96MA system (Pyrosequencing AB) PSQ96MA 2.0.1 software. The procedure has been previously described in detail $(21,22)$.

\section{Statistical analysis}

Statistical analyses were performed with the Statistical Package for Social Sciences software (SPSS, version 13.0 for Windows; SPSS Inc, Chicago, IL). The data are presented as means and SD in Tables 1 and 3. Quantitative effects on the selected anthropometric and food intake variables were tested in two- and three-way ANOVA/ANCOVA models with age group (children or adolescents), sex (girls or boys) and LCT-13910 C > T genotype CT/TT vs. CC (LNP vs. LP) as fixed factors. Adjustments for daily energy intake were performed using the residual method when body fat percentage was dependent variable in ANCOVA models.

\section{Ethics}

Parents and 15-year olds gave specific written informed consent to participation in the present genetic study. The study was approved by the Research Ethics Committees of Örebro County Council and Huddinge University Hospital.

\section{Results}

The baseline characteristics of both girls and boys are shown in Table 1. Analysis of the LCT-13910 C > T genotype showed that the CT and TT genotypes, associated with LP, were found in $261(87.0 \%)$ children and $329(85.2 \%)$ adolescent subjects. The genotype LCT$13910 \mathrm{CC}$ that is associated with LNP was found in 37 children (13.0\%) and 57 adolescents (14.8\%).

Table 2 shows an analysis of the overall effect of the LCT-13910 C $>$ T polymorphism on the studied variables using the levels TT/CT vs. CC in a three-way ANCOVA/ ANOVA model. Taken together, milk, soured milk and yoghurt intakes, specifically intakes of reduced fat 
Table 1. Anthropometric characteristics, total energy intake (kJ/day) and dietary intake (g/day) at baseline $(N=686)$

\begin{tabular}{|c|c|c|c|c|}
\hline & \multicolumn{2}{|c|}{ Children } & \multicolumn{2}{|c|}{ Adolescents } \\
\hline & Girls $(n=138)$ & Boys $(n=162)$ & Girls $(n=196)$ & Boys $(n=190)$ \\
\hline Age (years) & $9.6 \pm 0.4$ & $9.6 \pm 0.3$ & $15.6 \pm 0.4$ & $15.6 \pm 0.4$ \\
\hline Height (cm) & $138 \pm 6.3$ & $139 \pm 5.7$ & $165 \pm 6.4$ & $176 \pm 7.7$ \\
\hline Weight (kg) & $33.5 \pm 6.0$ & $33.2 \pm 5.6$ & $56.9 \pm 7.8$ & $64.1 \pm 10.7$ \\
\hline BMI $\left(\mathrm{kg} / \mathrm{m}^{2}\right)$ & $17.3 \pm 2.1$ & $17.1 \pm 2.2$ & $20.9 \pm 2.4$ & $20.6 \pm 2.6$ \\
\hline Waist circumference $(\mathrm{cm})$ & $60.1 \pm 5.4$ & $60.5 \pm 5.4$ & $69.2 \pm 5.7$ & $73.5 \pm 7.0$ \\
\hline Body fat (\%) & $18.5 \pm 5.3$ & $15.8 \pm 5.8$ & $22.6 \pm 4.1$ & $13.0 \pm 5.6$ \\
\hline Energy intake (kJ/day) & $8,481 \pm 1,920$ & $8,891 \pm 2,368$ & $8,753 \pm 2,665$ & $12,372 \pm 3,686$ \\
\hline Milk, soured milk and yoghurt intake (g/day) & $562 \pm 315$ & $683 \pm 340$ & $501 \pm 380$ & $801 \pm 521$ \\
\hline Full-fat milk, soured milk and yoghurt intake (g/day) & $218 \pm 286$ & $253 \pm 292$ & $134 \pm 233$ & $246 \pm 381$ \\
\hline Reduced fat milk, soured milk and yoghurt intake (g/day) & $352 \pm 295$ & $423 \pm 392$ & $367 \pm 343$ & $579 \pm 477$ \\
\hline Milk intake (g/day) & $489 \pm 291$ & $566 \pm 367$ & $410 \pm 345$ & $696 \pm 477$ \\
\hline Full-fat milk (g/day) & $149 \pm 230$ & $162 \pm 249$ & $67 \pm 185$ & $151 \pm 325$ \\
\hline Reduced fat milk (g/day) & $339 \pm 292$ & $404 \pm 368$ & $342 \pm 334$ & $544 \pm 466$ \\
\hline Soured milk intake (g/day) & $48 \pm 118$ & $78 \pm 169$ & $52 \pm 126$ & $80 \pm 192$ \\
\hline Full-fat soured milk (g/day) & $42 \pm 112$ & $62 \pm 157$ & $41 \pm 119$ & $58 \pm 172$ \\
\hline Reduced fat soured milk (g/day) & $6.5 \pm 44$ & $16 \pm 7 \mid$ & $1 \mathrm{II} \pm 50$ & $22 \pm 106$ \\
\hline Yoghurt intake (g/day) & $33 \pm 101$ & $32 \pm 101$ & $39 \pm 109$ & $51 \pm 138$ \\
\hline Full-fat yoghurt (g/day) & $27 \pm 95$ & $29 \pm 97$ & $25 \pm 82$ & $37 \pm 120$ \\
\hline Reduced fat yoghurt (g/day) & $5.9 \pm 40$ & $3.1 \pm 29$ & $14 \pm 77$ & $13 \pm 70$ \\
\hline Cheese intake (g/day) & $18 \pm 33$ & $23 \pm 38$ & $30 \pm 39$ & $47 \pm 63$ \\
\hline Cream intake (g/day) & $4.4 \pm 16$ & $2.2 \pm 9$ & $5.6 \pm 22$ & $6.1 \pm 30$ \\
\hline Ice cream intake (g/day) & $21 \pm 39$ & $19 \pm 44$ & $13 \pm 35$ & $21 \pm 52$ \\
\hline \multicolumn{5}{|l|}{ LCT-genotype [n (\%)] } \\
\hline $\mathrm{CC}$ & $19(13.8)$ & $18(1 \mathrm{I} .1)$ & $28(14.3)$ & $29(15.3)$ \\
\hline $\mathrm{CT}$ & $55(40.0)$ & $65(40.1)$ & $77(39.3)$ & $76(40.0)$ \\
\hline TT & $63(46.2)$ & $78(48.8)$ & 91 (46.4) & 85 (44.7) \\
\hline
\end{tabular}

versions, were significantly lower in individuals with LNP $(p<0.001)$. Analysed separately, milk intake $(\mathrm{g} / \mathrm{d})$ and specifically reduced fat milk $(\mathrm{g} / \mathrm{d})$ was lower $(p=0.001$ and $p<0.001$, respectively) in LNP children and adolescents. Body fat percentage (adjusted and unadjusted for energy intake) as well as daily energy intake were not related to the LCT-13910 C > T genotype.

Table 2 presents the distribution of milk and milk product intake-related variables, which were significantly related to the genotype in Table 2, stratified for age group and sex, and according to LCT-13910 C > T genotypes.

As shown in Table 3, after subsequent partitioning of milk and milk product intake-related variables, the LCT13910 CC genotype was associated with statistically significantly lower intake of total milk, soured milk and yoghurt ( $p=0.002$ for children and $p=0.023$ for adolescents). Milk intake was significantly lower in LNP children $(p=0.005)$ and in LNP adolescents $(p=0.043)$ compared to LP children and adolescents. Analysed by fat content, the $\mathrm{CC}$ genotype was associated with significantly lower intake of total reduced fat milk, soured milk and yoghurt, in both children and adolescents ( $p=0.009$ and $p=0.019$, respectively). Reduced fat milk intake was also significantly lower in LNP children and adolescents ( $p=0.010$ and $p=0.001$, respectively).

No statistically significant interactions of the LCT$13910 \mathrm{C}>\mathrm{T}$ polymorphism with age and sex for the selected variables were found in either the two-way ANCOVA/ANOVA or three-way ANCOVA/ANOVA models.

In response to a question about the presence of chronic conditions in, or adherence to special diets by, their children, parents reported lactose intolerance in just six cases (two children and four adolescents). None of these cases demonstrated genetically determined LNP.

\section{Discussion}

We conducted the current study to investigate the possible differences in dairy product intake and in body fat mass among LP and LNP children and adolescents. 
Table 2. Effects of genotype, sex and age group, on total energy intake (kJ/day), dietary intake (g/day) and body fat $(\%)$

\begin{tabular}{|c|c|c|c|}
\hline Effect & Genotype & Sex & Age group \\
\hline$P$ value $^{\mathrm{a}}$ & $(P)$ & $(P)$ & $(P)$ \\
\hline Body fat ${ }^{b}$ & 0.906 & $<0.001$ & 0.075 \\
\hline Energy & 0.407 & $<0.001$ & $<0.001$ \\
\hline Milk, soured milk and yoghurt & $<0.001$ & 0.223 & 0.258 \\
\hline $\begin{array}{l}\text { Full-fat milk, soured milk and } \\
\text { yoghurt }\end{array}$ & 0.588 & 0.754 & 0.061 \\
\hline $\begin{array}{l}\text { Reduced fat milk, soured milk } \\
\text { and yoghurt }\end{array}$ & $<0.001$ & 0.140 & 0.739 \\
\hline Milk & 0.001 & 0.224 & 0.313 \\
\hline Full-fat milk & 0.246 & 0.581 & 0.091 \\
\hline Reduced fat milk & $<0.001$ & 0.116 & 0.867 \\
\hline Soured milk & 0.320 & 0.438 & 0.941 \\
\hline Full-fat soured milk & 0.495 & 0.759 & 0.586 \\
\hline Reduced fat soured milk & 0.427 & 0.291 & 0.225 \\
\hline Yoghurt & 0.502 & 0.392 & 0.486 \\
\hline Full-fat yoghurt & 0.749 & 0.989 & 0.597 \\
\hline Reduced fat yoghurt & 0.461 & 0.101 & 0.661 \\
\hline Cheese & 0.255 & 0.467 & 0.294 \\
\hline Cream & 0.901 & 0.780 & 0.889 \\
\hline Ice cream & 0.680 & 0.919 & 0.469 \\
\hline
\end{tabular}

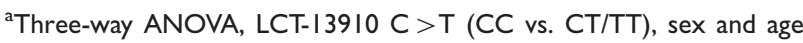
group as factors.

${ }^{\text {b}}$ Three-way ANCOVA, LCT-I3910 C > T (CC vs. CT/TT), sex and age group as factors; adjusted for daily energy intake $(\mathrm{kJ} / \mathrm{d})$.
There was a statistically significant difference between milk and milk product consumption in LP and LNP subjects. LNP was associated with a lower consumption of milk, soured milk and yoghurt. Interestingly, LP children and adolescents consumed statistically significantly more reduced fat milk than LNP subjects.

Concerning the key question of our study, whether LP and LNP influence the consumption of milk and milk products, which in turn could be associated with differences in body fat mass, we found no differences between LP and LNP as regards body fat mass.

A recent study, performed on the National Health and Nutrition Survey (NHANES) 1999-2004, showed that a dietary pattern characterised by greater milk intake was associated with increased BMI among preschool children (23). Sweden has traditionally one of the highest consumption rates of milk in the world (24) and we hypothesise that the potential physiologic effects of single food components, such as milk and milk products, may differ between countries due to their particular food and farming culture, agricultural inheritance and geographical as well as climatic singularities.

The higher consumption of reduced fat milk, compared to full-fat milk, in all age and genotype groups might reflect a secular trend. Krachler et al. (25) reported in 2005 a switch from $3 \%$ of fat milk to $1.5 \%$ of fat milk among northern Swedes that occurred between 1986 and 1999.

About $83 \%$ of the LNP individuals consumed some amount of milk. On average, they consumed $421 \mathrm{~g}(95 \%$ CI 399, 502) milk per day. This is compatible with many

Table 3. Effects of genotype on milk intake related variables significant in Table 2 (stratified by age group)

\begin{tabular}{|c|c|c|c|c|c|c|}
\hline Genotype & Age & Sex & $\begin{array}{l}\text { Milk, soured milk } \\
\text { and yoghurt }\end{array}$ & $\begin{array}{l}\text { Reduced fat milk, soured } \\
\text { milk and yoghurt }\end{array}$ & $\begin{array}{c}\text { Milk intake } \\
\text { (g/day) }\end{array}$ & $\begin{array}{l}\text { Reduced fat milk } \\
\text { (g/day) }\end{array}$ \\
\hline \multirow[t]{4}{*}{$\mathrm{CC}$} & Children & Girls & $471 \pm 299$ & $269 \pm 235$ & $412 \pm 276$ & $203 \pm 292$ \\
\hline & & Boys & $427 \pm 192$ & $355 \pm 316$ & $352 \pm 183$ & $269 \pm 235$ \\
\hline & Adolescents & Girls & $381 \pm 328$ & $202 \pm 265$ & $313 \pm 294$ & $190 \pm 260$ \\
\hline & & Boys & $380 \pm 636$ & $387 \pm 436$ & $573 \pm 576$ & $365 \pm 428$ \\
\hline \multirow[t]{4}{*}{ CT } & Children & Girls & $577 \pm 330$ & $355 \pm 316$ & $477 \pm 304$ & $339 \pm 315$ \\
\hline & & Boys & $689 \pm 435$ & $442 \pm 421$ & $597 \pm 412$ & $427 \pm 402$ \\
\hline & Adolescents & Girls & $891 \pm 516$ & $390 \pm 629$ & $424 \pm 734$ & $368 \pm 390$ \\
\hline & & Boys & $891 \pm 557$ & $629 \pm 510$ & $734 \pm 502$ & $581 \pm 497$ \\
\hline \multirow[t]{4}{*}{ TT } & Children & Girls & $598 \pm 306$ & $390 \pm 291$ & $524 \pm 287$ & $381 \pm 290$ \\
\hline & & Boys & $717 \pm 380$ & $438 \pm 397$ & $582 \pm 344$ & $4|2 \pm 36|$ \\
\hline & Adolescents & Girls & $525 \pm 343$ & $428 \pm 306$ & $428 \pm 306$ & $368 \pm 290$ \\
\hline & & Boys & $817 \pm 434$ & $703 \pm 411$ & $703 \pm 411$ & $572 \pm 440$ \\
\hline Effect $\mathrm{LCT}^{\mathrm{a}}$ & Children & & $0.002^{b}$ & $0.009^{b}$ & $0.005^{b}$ & $0.010^{\mathrm{b}}$ \\
\hline$(P)$ & Adolescents & & $0.023^{b}$ & $0.019^{b}$ & $0.043^{b}$ & $0.001^{b}$ \\
\hline
\end{tabular}

aLCT-I3910 C $>$ T polymorphism.

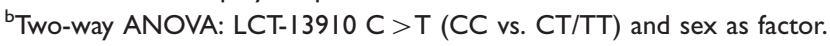


studies showing that LNP subjects can tolerate a certain amount of lactose intake per day $(6,26-28)$.

Concerning the high prevalence of LNP (14\%) compared to the traditional prevalence data of LNP in Sweden $(2 \%)$, we have found a trend towards an increasing prevalence of LNP in Sweden. This increase seems to have taken place in the course of the second half of the twentieth century due to higher immigration rates to Sweden after the Second World War (29).

The strengths to be considered in this study are that we use the concept of Mendelian randomisation (MR), by subdividing genotypes in LP and LNP, to readdress the question of whether nutrigenetically defined factors, like milk and milk product intake, affect body fat mass in children and adolescents. MR studies modifiable causes of disease in genetic epidemiology. A functional genetic variant, in our study LCT-13910 C $>$ T polymorphism, acts as proxy for modifiable lifetime exposure patterns, i.e. milk consumption. The LCT-13910 C $>\mathrm{T}$ polymorphism is known to influence the exposure pattern, milk consumption (2, 5, 6, 30-32). In addition, we analysed both, full fat and reduced fat varieties as regards the key question of this work.

Limitations of this study include the drawbacks inherent to 24-hour dietary recall, which may not fully reflect long-term food intake behaviour (33). Yet the genetically determined condition of LP or LNP, which we studied in this work, is not subject to changes during life. The results should be interpreted bearing in mind the limitations inherent in any cross-sectional study. Furthermore, results of genetic epidemiological studies obtained in one defined population should not be applied without reserve to other populations or ethnic groups.

The age of onset of LNP shows a wide regional and ethnical variation (4). In persons of European descent, the onset of genetically determined LNP is rarely seen before five years of age (34-36); Finnish children who develop LNP have done so by the age of 10 (4). Thus, it could be assumed that the majority of children and almost all adolescents with LCT-13910 CC genotype had developed manifest LNP at the time of inclusion in this study. However, the correlation between LNP and selfreported 'lactose intolerance' has been previously suggested to be poor (37-39), which we confirm in this study: six cases parents reported 'lactose intolerance' in their children, in two children and four adolescents, and none of them were LNP according to genotyping data.

In conclusion, LP is linked to an overall higher milk and dairy intake, but is not linked to higher measures of body fat mass in children and adolescents.

\section{Acknowledgements}

We thank the Stockholm County Council, Sweden, for creating and guaranteeing the study base. We are grateful to Associate Professor
Olle Carlsson for statistical advice and Lewis Burgess, Ph.D., applied anthropologist in New York City for revising the manuscript.

\section{Conflict of interest and funding}

This study was supported by grants from Örebro Läns Landstings Forskningskommitté and by Nyckelfonden, Örebro, Sweden.

\section{References}

1. Swallow DM. Genetics of lactase persistence and lactose intolerance. Annu Rev Genet 2003; 37: 197-219.

2. Enattah NS, Trudeau A, Pimenoff V, Maiuri L, Auricchio S, Greco L, et al. Evidence of still-ongoing convergence evolution of the lactase persistence T-13910 alleles in humans. Am J Hum Genet 2007; 81: 615-25

3. Enattah NS, Sahi T, Savilahti E, Terwilliger JD, Peltonen L, Järvelä I. Identification of a variant associated with adult-type hypolactasia. Nat Genet 2002; 30: 233-7.

4. Rasinperä H, Savilahti E, Enattah NS, Kuokkanen M, Tøtterman N, Lindahl H, et al. A genetic test which can be used to diagnose adult-type hypolactasia in children. Gut 2004; 53: 1571-6.

5. Sahi T. Genetics and epidemiology of adult-type hypolactasia. Scand J Gastroenterol Suppl 1994; 202: 7-20.

6. Suarez FL, Savaiano D, Arbisi P, Levitt MD. Tolerance to the daily ingestion of two cups of milk by individuals claiming lactose intolerance. Am J Clin Nutr 1997; 65: 1502-6.

7. Barba G, Troiano E, Russo P, Venezia A, Siani A. Inverse association between body mass and frequency of milk consumption in children. Br J Nutr 2005; 93: 15-9.

8. Carruth BR, Skinner JD. The role of dietary calcium and other nutrients in moderating body fat in preschool children. Int $\mathbf{J}$ Obes Relat Metab Disord 2001; 25: 559-66.

9. Moore LL, Bradlee ML, Gao D, Singer MR. Low dairy intake in early childhood predicts excess body fat gain. Obesity (Silver Spring) 2006; 14: 1010-8.

10. Novotny R, Daida YG, Acharya S, Grove JS, Vogt TM. Dairy intake is associated with lower body fat and soda intake with greater weight in adolescent girls. J Nutr 2004; 134: 1905-9.

11. Gunther CW, Legowski PA, Lyle RM, McCabe GP, Eagan MS, Peacock M, et al. Dairy products do not lead to alterations in body weight or fat mass in young women in a 1-y intervention. Am J Clin Nutr 2005; 81: 751-6.

12. Murakami K, Okubo H, Sasaki S. No relation between intakes of calcium and dairy products and body mass index in Japanese women aged 18 to $20 \mathrm{y}$. Nutrition 2006; 22: 490-5.

13. Newby PK, Peterson KE, Berkey CS, Leppert J, Willett WC, Colditz GA. Beverage consumption is not associated with changes in weight and body mass index among low-income preschool children in North Dakota. J Am Diet Assoc 2004; 104: 1086-94.

14. Phillips SM, Bandini LG, Cyr H, Colclough-Douglas S, Naumova E, Must A. Dairy food consumption and body weight and fatness studied longitudinally over the adolescent period. Int J Obes Relat Metab Disord 2003; 27: 1106-13.

15. Berkey CS, Rockett HR, Willett WC, Colditz GA. Milk, dairy fat, dietary calcium, and weight gain: a longitudinal study of adolescents. Arch Pediatr Adolesc Med 2005; 159: 543-50.

16. Slyper A, Huang W-M. Milk, dairy fat, and body weight in pediatrics: time for reappraisal. Infant Child Adolesc Nutr 2009; 1: $148-59$.

17. Wennlöf AH, Yngve A, Sjöström M. Sampling procedure, participation rates and representativeness in the Swedish part 
of the European Youth Heart Study (EYHS). Public Health Nutr 2003; 6: 291-9.

18. Wennlöf AH, Yngve A, Nilsson TK, Sjöström M. Serum lipids, glucose and insulin levels in healthy schoolchildren aged 9 and 15 years from Central Sweden: reference values in relation to biological, social and lifestyle factors. Scand J Clin Lab Invest 2005; 65: 65-76.

19. Slaughter MH, Lohman TG, Boileau RA, Horswill CA, Stillman RJ, Van Loan MD, et al. Skinfold equations for estimation of body fatness in children and youth. Hum Biol 1988; 60: 70923.

20. Gutin B, Litaker M, Islam S, Manos T, Smith C, Treiber F. Body-composition measurement in 9-11-y-old children by dualenergy X-ray absorptiometry, skinfold-thickness measurements, and bioimpedance analysis. Am J Clin Nutr 1996; 63: 287-92.

21. Nilsson TK, Johansson CA. A novel method for diagnosis of adult hypolactasia by genotyping of the $-13910 \mathrm{C} / \mathrm{T}$ polymorphism with pyrosequencing technology. Scand $\mathrm{J}$ Gastroenterol 2004; 39: 287-90.

22. Nilsson TK, Olsson LA. Simultaneous genotyping of the three lactose tolerance-linked polymorphisms LCT-13907 C $>\mathrm{G}$, LCT-13910 C > T and LCT-13915 T > G with pyrosequencing technology. Clin Chem Lab Med 2008; 46: 80-4.

23. Wiley AS. Dairy and milk consumption and child growth: Is BMI involved? An analysis of NHANES 1999-2004. Am J Hum Biol. 2010; 22: 517-25.

24. Hjartaker A, Lagiou A, Slimani N, Lund E, Chirlaque MD, Vasilopoulou E, et al. Consumption of dairy products in the European Prospective Investigation into Cancer and Nutrition (EPIC) cohort: data from 35,955 24-hour dietary recalls in 10 European countries. Public Health Nutr 2002; 5: 1259-71.

25. Krachler B, Eliasson MC, Johansson I, Hallmans G, Lindahl B. Trends in food intakes in Swedish adults 1986-1999: findings from the Northern Sweden MONICA (Monitoring of Trends and Determinants in Cardiovascular Disease) Study. Public Health Nutr 2005; 8: 628-35.

26. Savaiano DA, Boushey CJ, McCabe GP. Lactose intolerance symptoms assessed by meta-analysis: a grain of truth that leads to exaggeration. J Nutr 2006; 136: 1107-13.

27. Byers KG, Savaiano DA. The myth of increased lactose intolerance in African-Americans. J Am Coll Nutr 2005; 24: 569S-73S.

28. Scrimshaw NS, Murray EB. The acceptability of milk and milk products in populations with a high prevalence of lactose intolerance. Am J Clin Nutr 1988; 48: 1079-159.

29. Almon R, Engfeldt P, Tysk C, Sjöström M, Nilsson TK. Prevalence and trends in adult-type hypolactasia in different age cohorts in Central Sweden diagnosed by genotyping for the adult-type hypolactasia-linked LCT-13910 C > T mutation. Scand J Gastroenterol 2007; 42: 165-70.

30. Ebrahim S, Davey Smith G. Mendelian randomization: can genetic epidemiology help redress the failures of observational epidemiology? Hum Genet 2008; 123: 15-33.

31. Davey Smith G, Ebrahim S. 'Mendelian randomization': can genetic epidemiology contribute to understanding environmental determinants of disease? Int J Epidemiol 2003; 32: 1-22.

32. Davey Smith G, Ebrahim S. What can Mendelian randomisation tell us about modifiable behavioural and environmental exposures? BMJ 2005; 330: 1076-9.

33. Klesges RC, Eck LH, Ray JW. Who underreports dietary intake in a dietary recall? Evidence from the Second National Health and Nutrition Examination Survey. J Consult Clin Psychol 1995; 63: 438-44.

34. Welsh JD, Poley JR, Bhatia M, Stevenson DE. Intestinal disaccharidase activities in relation to age, race, and mucosal damage. Gastroenterology 1978; 75: 847-55.

35. Simoons FJ. Age of onset of lactose malabsorption. Pediatrics 1980; 66: 646-8.

36. Keusch GT, Troncale FJ, Thavaramara B, Prinyanont P, Anderson PR, Bhamarapravathi N. Lactase deficiency in Thailand: effect of prolonged lactose feeding. Am J Clin Nutr 1969; 22: $638-41$

37. Gugatschka M, Dobnig H, Fahrleitner-Pammer A, Pietschmann P, Kudlacek S, Strele A, et al. Molecularly-defined lactose malabsorption, milk consumption and anthropometric differences in adult males. QJM 2005; 98: 857-63.

38. Enattah N, Pekkarinen T, Välimäki MJ, Loyttyniemi E, Järvelä I. Genetically defined adult-type hypolactasia and self-reported lactose intolerance as risk factors of osteoporosis in Finnish postmenopausal women. Eur J Clin Nutr 2005; 59: 1105-11.

39. Lehtimäki T, Hemminki J, Rontu R, Mikkila V, Rasanen L, Laaksonen $\mathrm{M}$, et al. The effects of adult-type hypolactasia on body height growth and dietary calcium intake from childhood into young adulthood: a 21-year follow-up study - the Cardiovascular Risk in Young Finns Study. Pediatrics 2006; 118: $1553-9$.

\footnotetext{
*Ricardo Almon

Family Medicine Research Centre

School of Health and Medical Sciences

Örebro University

Box 1613, Örebro S 701 16, Sweden

Tel: +46196025789

Fax: +46196025797

Email: ricardo.almon@orebroll.se
} 